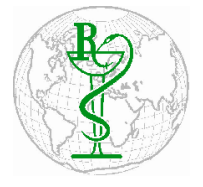

INDO GLOBAL JOURNAL OF

PHARMACEUTICAL SCIENCES

ISSN 2249- 1023

\title{
Phytochemical Screening and Novel Synthesis of Silver Nanoparticles Using Peels of Punica Granatum
}

\author{
Richa Sharma *, Vijaylaxmee Mishra, Basant Chaudhary \\ Department of Biotechnology and Food Sciences, Jayoti Vidyapeeth Women's University, Jharna, Jaipur-303122, Rajasthan, India \\ Address for Correspondence: Richa Sharma; richa.phd.15@gmail.com
}

\begin{abstract}
The green synthesis of nanoparticles is an expanding research area due to the potential applications for the developmental of novel techniques. The study aims to investigate a versatile technique for the novel synthesis of nanoparticles using the ethanolic extract of Punica granatum peels for the presence of various phytochemical screening. The plant belongs to family Punicaceae and the plant having promising medicinal properties for a wide range of human disease. The presence of various phytochemicals viz. alkaloids glycosides, carbohydrates, steroids, phytosterol, flavonoids, protein \& amino acid, phenol \& tannins and saponins were investigated by following standard biochemical method. The novel synthesis of nanoparticles with the aqueous solution of $\mathrm{AgNO}_{3}$ after addition of plant extract the color changes of the solution started time within 10 minutes to 24 hours from light yellow to dark brown. The synthesized silver nanoparticles characterized by the UV-Visible spectroscopy, revealed the formation of silver nanoparticles by exhibiting the typical surface Plasmon absorption 346nm (10min.), 369nm (20min.), 377nm (30min.), 380nm (1 hour) and 456nm (24 hour) respectively. The ethanolic extract of Punica granatum peels is a very good bioreductant for the novel synthesis of silver nanoparticles and further characterization and antimicrobial activity of nanoparticles was under progress. (c) 2014 iGlobal Research and Publishing Foundation. All rights reserved.
\end{abstract}

Conference Proceedings: International Conference on Life Sciences, Informatics, Food and Environment; August 2930, 2014

Indo Global Journal of Pharmaceutical Sciences( ISSN 22491023 ; CODEN- IGJPAI; NLM ID: 101610675) indexed and abstracted in EMBASE(Elsevier), SCIRUS(Elsevier),CABI, CAB Abstracts, Chemical Abstract Services(CAS), American Chemical Society(ACS), Index Copernicus, EBSCO, DOAJ, Google Scholar and many more. For further details, visit 